\title{
Construction of detours of rail nodes, as an effective way to increase the throughput
}

\author{
Denis Kuklev', Natalya Kukleva ${ }^{1, *}$ \\ ${ }^{1}$ Far Eastern State Transport University (FESTU), 680021 Khabarovsk, Russia
}

\begin{abstract}
In the article the question of the justification of expediency of the construction of bypasses junctions, intended for the admission of transit freight trains. According to the authors, on the basis of the most important factors, were considered the possible combinations of the length of the bypass and the intra-site the main ways. On the example of the conventional rail node, the results of the calculations, which allowed us to make inferences that require expansion and refinement in future studies.
\end{abstract}

\section{Introduction}

Increase of the capacity of railway nodes is an important task, the solution of which operate the railroad around the world. One of the frequently used methods is to increase the capacity of the node device through the construction of additional tracks (main, receiving and departure track) [1], which leads to fairly high costs both in investment and technology, because it requires to conduct construction works in the period of operation of the facility. To achieve the results and in other ways, for example, in Italy in railway stations in Rome and Milan by 2018 it is planned to introduce a system to reduce significantly the intervals between trains $[2,3]$. One of the most effective ways to increase the capacity of railway nodes, and the elimination of difficulties in their work is the construction of detours for the passage of transit trains. Construction of bypasses is one of the only activities that increases the capacity of the railway nodes. It applies equally to passenger and cargo movement. For example, to pass high-speed passenger trains without entering the Paris node be the 1994 was built a bypass that allowed to accelerate the promotion of high-speed trains of the southern and Northern high-speed railway lines, reducing travel time for passengers between Lille and Lyon-3 hours, and between Lille and Marseille - up to 6 hours. The commissioning of the bypass Nimes - Montpellier it is planned in 2017 [4]. In Germany, the bypass railway junction Hamburg helped to make the routes of freight trains from the Central areas of the city. Bypassing of nodes was based in Hannover (via Elze to Braunschweig), the stowage of the new bypass in Bebra has eliminated the need to turn trains the message from Frankfurt to Berlin, the travel time from Frankfurt to Erfurt was reduced for 40 minutes, in Leipzig - 55 minutes. These examples and many others (Brasil [5], France [6], Slovenia [7], China [8], USA [9]) indicate that bypassing of nodes, among other activities, successfully applied to decongest the existing railway junctions, pushing deadlines necessary to strengthen them.

\footnotetext{
* Corresponding author: Kukleva.natalya@bk.ru
} 
However, hasn't resolved yet the question of scientific substantiation of expediency of the construction of the railway crawls sites that are designed at the first stage, for facilitating the transit of freight trains without entering as into the separate areas and station node and the railway junction as a whole. This article focuses on the feasibility of constructing a bypass given the breakdown of the development of the conventional railway junction (Figure 1) at each stage.

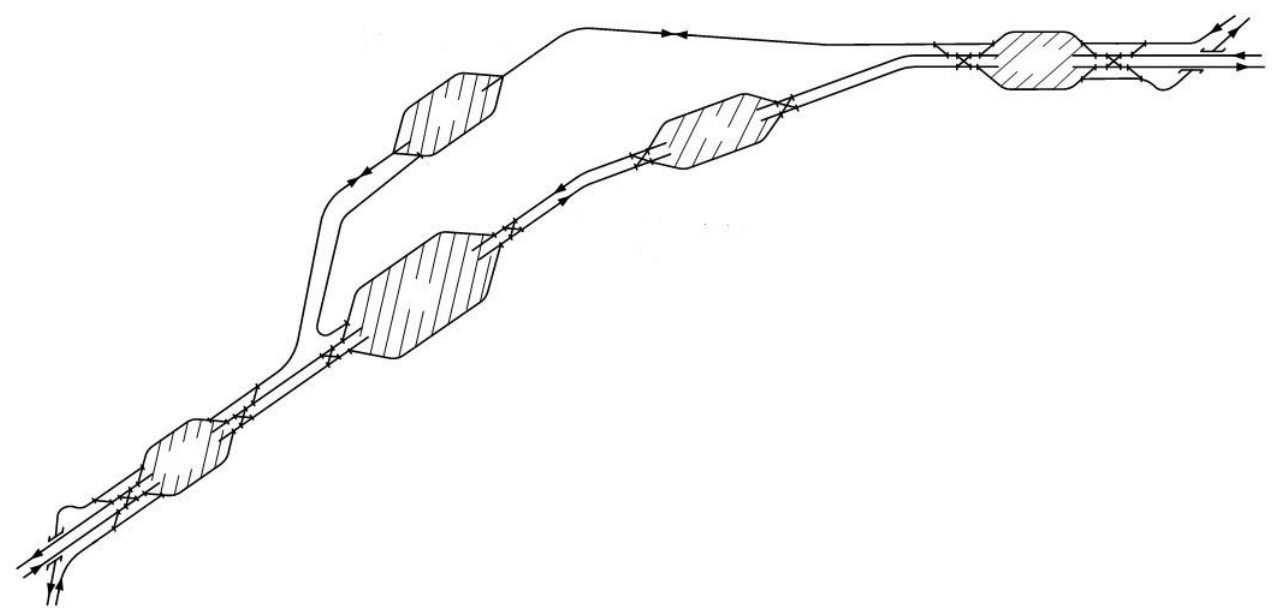

Fig. 1. Scheme of conventional railway junction with the bypass: PS - prenodal station, S switchyard; P - passenger stations; PS- the precinct station on the bypass.

\section{Statement of the problem}

The issue of construction of bypass railway junction occurs if the bandwidth of the main ways intrasite or receiving and departure track designed for transit freight trains is not sufficient to permit flow of these trains without delay. The construction of the bypass railway junction at a certain stage of its development is considered as an alternative solution to strengthen motion progress with the aim of increasing the bandwidth of its stages and receiving and departure tracks to handle transit freight trains in the station, most of the sorting.

The boundary values of the sizes of movement of transit cargo trains, in which the construction of the bypass node becomes cost-effective, depends on a number of factors, the main ones are [10]:

- The size, nature and timetable of passenger trains in the node and on approaches to it in the period of maximum transport (summer). This factor determines the time spent in the host cargo transit trains, their delays due to crossing of passenger trains;

- Overall dimensions of cargo movements, of which less transit trains, the number of turns of the trains that cannot be rejected on the bypass (for trains arriving to and dissolution of its formation);

- Bandwidth of the main ways of intrasite course;

- The number of ways in receiving and departure tracks, dedicated for the transit of trains;

- The ratio of the length of the bypass and intrasite turn, determines the run of the rolling stock through the following options;

- Scheme of traction service freight trains, to determine whether construction on the bypass devices for maintenance and equipment train locomotives, or the absence of such devices; 
- Topographic, urban planning and other local conditions affecting the cost of construction of the bypass path and the node device during the reconstruction of the intrasite course (stations, spans);

- The volume and conditions of production of construction works in the construction of a bypass and installation of additional mainline track on the progress and intrasite receiving and departure track's ways for transit trains in the switchyard.

As one of the original provisions in determining the terms and boundaries of the feasibility of the construction of the bypass is assumed that the gain of the device node to the processed traffic volume, and development of other stations will be the same as in the construction of the bypass, and the strengthening of intrasite course.

\section{The characteristics of possible variants in the construction of the bypass}

One of the factors that significantly affect the ratio of capital expenditures and operating expenses in the construction of the bypass and strengthening intrasite speed is the ratio of their lengths.

To design crawls of the railway junctions the two options are possible:

option I - the length of the bypass is less than the length of intrasite course;

option II - bypass length is greater than the length of intrasite course.

If the length of the bypass is less than the length of intrasite course, as a rule:

- Investments in the construction of the bypass is less than for option gain of intrasite course;

- Operating costs associated with mileage transit freight trains and the time spent in the node is less than the bypass.

If the length of the bypass is greater than the length intrasite course, then the two options are possible:

1. Construction costs of the bypass, there is less gain intrasite courses;

2. The cost of construction of a bypass are more than the cost for the strengthening of intrasite course.

However, current expenses associated with mileage of transit freight trains will tend to be smaller in the embodiment of the gain node, and the expenses associated with the residence time of these trains in the railway border node can be either higher or lower. This will depend on the fact of how the length of the bypass is greater than the length of the intrasite course.

Among the options considered in the ratio of investment in the second option will be beneficial to strengthening intrasite course.

In the first construction of the bypass will be beneficial in the case that additional investments to strengthen intrasite progress will not be repaid in a reasonable period due to savings on operating costs associated with mileage transit freight trains and the time spent in the node.

Possible ratios cash (existing) and required (necessary) capacity of receiving and departure track's for transit trains $\left(N_{e x}^{r-d}, N_{n}^{r-d}\right)$, hauls intrasite course $\left(N_{e x}^{i c}, N_{n}^{i c}\right)$, as well as lengths of bypass $\left(L_{b p}\right)$ and intrasite course $\left(L_{i c}\right)$ are given in table 1 . In table. 2 . the characteristics of each of the options and the possible benefits are shown that point to the benefits of bypass railway junction for the passage of transit trains. 
Table 1. Possible ratios.

\begin{tabular}{|c|c|c|c|}
\hline $\begin{array}{c}\text { № } \\
\text { var. }\end{array}$ & $N_{e x}^{i c} \& N_{n}^{i c}$ & $N_{e x}^{r-d} \& N_{e x}^{r-d}$ & Ratios \\
\hline 1 & $N_{e x}^{i c}>N_{n}^{i c}$ & $N_{e x}^{r-d}>N_{e x}^{r-d}$ & $L_{b p}>L_{i c}$ \\
\hline 2 & $N_{e x}^{i c}>N_{n}^{i c}$ & $N_{e x}^{r-d}>N_{e x}^{r-d}$ & $L_{b p}<L_{i c}$ \\
\hline 3 & $N_{e x}^{i c}>N_{n}^{i c}$ & $N_{e x}^{r-d}<N_{e x}^{r-d}$ & $L_{b p}>L_{i c}$ \\
\hline 4 & $N_{e x}^{i c}>N_{n}^{i c}$ & $N_{e x}^{r-d}<N_{e x}^{r-d}$ & $L_{b p}<L_{i c}$ \\
\hline 5 & $N_{e x}^{i c}<N_{n}^{i c}$ & $N_{e x}^{r-d}>N_{e x}^{r-d}$ & $L_{b p}>L_{i c}$ \\
\hline 6 & $N_{e x}^{i c}<N_{n}^{i c}$ & $N_{e x}^{r-d}>N_{e x}^{r-d}$ & $L_{b p}<L_{i c}$ \\
\hline 7 & $N_{e x}^{i c}<N_{n}^{i c}$ & $N_{e x}^{r-d}<N_{e x}^{r-d}$ & $L_{b p}>L_{i c}$ \\
\hline 8 & $N_{e x}^{i c}<N_{n}^{i c}$ & $N_{e x}^{r-d}<N_{e x}^{r-d}$ & $L_{b p}<L_{i c}$ \\
\hline
\end{tabular}

Table 2. The characteristics of each of the options.

\begin{tabular}{|c|l|}
\hline $\begin{array}{c}\text { No } \\
\text { var. }\end{array}$ & $\begin{array}{l}\text { Due to what can be justified the construction of the bypass railway } \\
\text { junction }\end{array}$ \\
\hline 1 & To reduce the time spent by transit trains in the node \\
\hline 2 & To reduce of the run and time of transit trains in the bounds of the node \\
\hline 3 & $\begin{array}{l}\text { The Reduction in time of transit trains in the node; saving investments, } \\
\text { investments for laying of additional tracks in receiving and departure } \\
\text { track's parks for transit trains in the rail yard }\end{array}$ \\
\hline 4 & $\begin{array}{l}\text { To reduce of the run and time of transit trains within the boundaries of the } \\
\text { node; - saving investment for laying of additional tracks in receiving and } \\
\text { departure track's parks for transit trains in the rail yard }\end{array}$ \\
\hline 5 & $\begin{array}{l}\text { Reduction in time of transit trains in the node; saving investments in laying } \\
\text { more tracks intrasite course }\end{array}$ \\
\hline 6 & $\begin{array}{l}\text { Reduction in time of transit trains in the node; saving investments in laying } \\
\text { more tracks intrasite course; reduced run transit freight trains }\end{array}$ \\
\hline 7 & $\begin{array}{l}\text { Savings in laying more tracks of intrasite course and additional ways in } \\
\text { receiving and departure track's parks for transit trains in the rail yard }\end{array}$ \\
\hline 8 & $\begin{array}{l}\text { Saving in laying more tracks intrasite course and additional ways in } \\
\text { receiving and departure track's parks for transit trains in the rail yard; } \\
\text { reduced run of transit freight trains }\end{array}$ \\
\hline
\end{tabular}


The question is: how to develop a railway junction in terms of growth of transit and other traffic volumes to achieve acceptable economic costs. To justify the period of construction of the bypass railway junction, it is expedient to use the method of dynamic programming [11].

\section{Example of calculations to determine the feasibility of building of a bypass in the node}

Initial data for calculations to determine the feasibility of the construction of the railway bypass of the conditional node are:

- Dimensions of freight trains;

- Investments and operating costs for construction of the bypass;

- Investments and operating costs for the option of strengthening the railway junction.

For the study, it is assumed that in the node there is annual increasing of the size of the movement of all categories of freight trains with pace in 4 pairs of trains per year. Length of intrasite speed is assumed to be constant and equal to $35 \mathrm{~km}$, and the length of the bypass varies from 25 to $45 \mathrm{~km}$.

Below for the calculations were taken the following dimensions of the movement at the beginning of the reporting period: 48 pairs of freight trains per day with a ratio of transit and other freight trains $0,5 / 0,5$ increments of 2 pairs of trains every year.

In each of the basic options of the scheme of node were chosen five sub-options of a technical condition corresponding to the size of the traffic of transit freight trains from 24 to 64 pairs of trains. After continuous numbering of sub-options, the first five of them describe the original version of the technical state of the node (with double-track intrasite course) and a sequentially increasing number of receiving and departure track's ways for transit trains from 3 to 7 in each direction. Modifications from the sixth to the tenth characterize in the second variant the technical condition of the node of four-tracked intrasite speed and the same number of in receiving and departure track's ways for transit trains from 3 to 7 . When comparing the first with the third option sub-options from the sixth to the tenth characterize the node with the bypass and the number of in receiving and departure track's ways for transit trains at the precinct station of bypass from 3 to 7 in each Park.

The results of the calculations showed that under other equal conditions, the greatest impact on the economic feasibility of the construction of the bypass has a ratio of length of the bypass and intrasite course, which can be seen from the example in figures 2 and 3, where there are diagrams of transitions when the length of the intrasite speed of $35 \mathrm{~km}$ and the length of the bypass. From figure 2 it is seen that, for example, when the length of the bypass is $25 \mathrm{~km}$, the feasibility of its construction comes at the 6th year of operation, when the size of the movement of transit trains made 36 pairs of trains a day. If the length of the bypass will be $45 \mathrm{~km}$ long, term of profitability of its input is extended to 13 years of operation and occurs with the transit of 50 pairs of trains per day.

From figure 3 it can be seen that at the same lengths the transition from the existing technical state of the node to the option of strengthening intrasite progress and construction of the bypass occurs in almost one year, with 48 pairs of transit trains.

It was found that the increase in the extent of bypass by an amount equal to $40 \%$ of the length of the intrasite turn will lead to excess costs in not more than $5 \%$, indicating the feasibility of the construction of the bypass. 


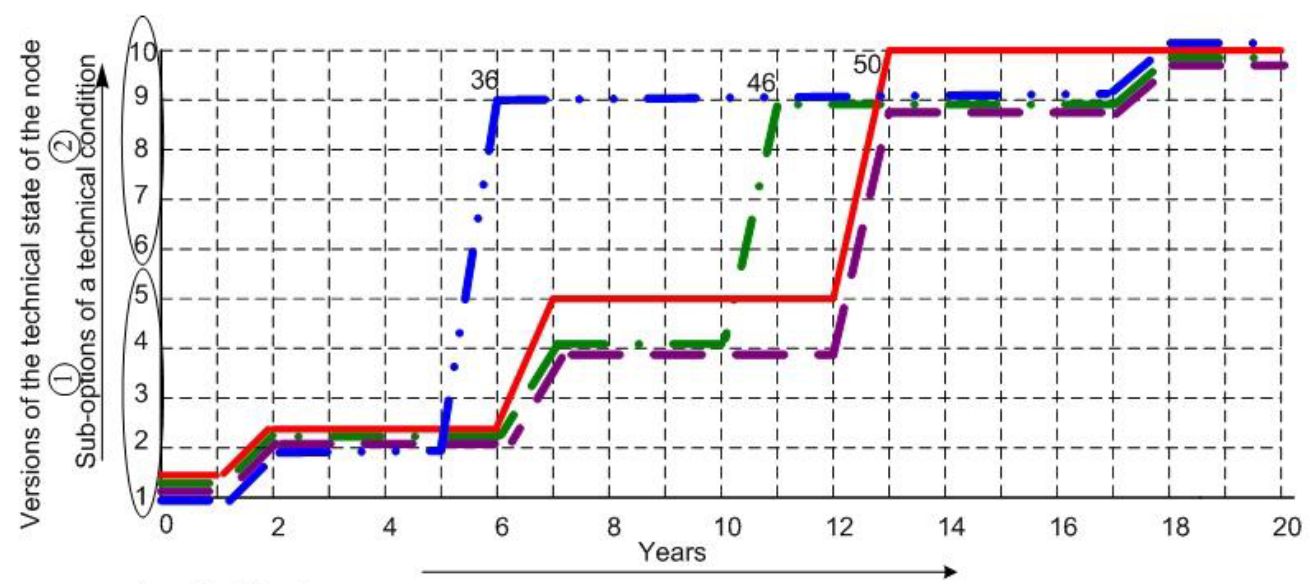

Length of the bypass

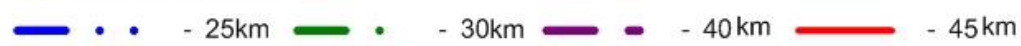

Figure 2. The dependence of the technical state of the node from the dimensions of motion at different length of the bypass and intrasite course.

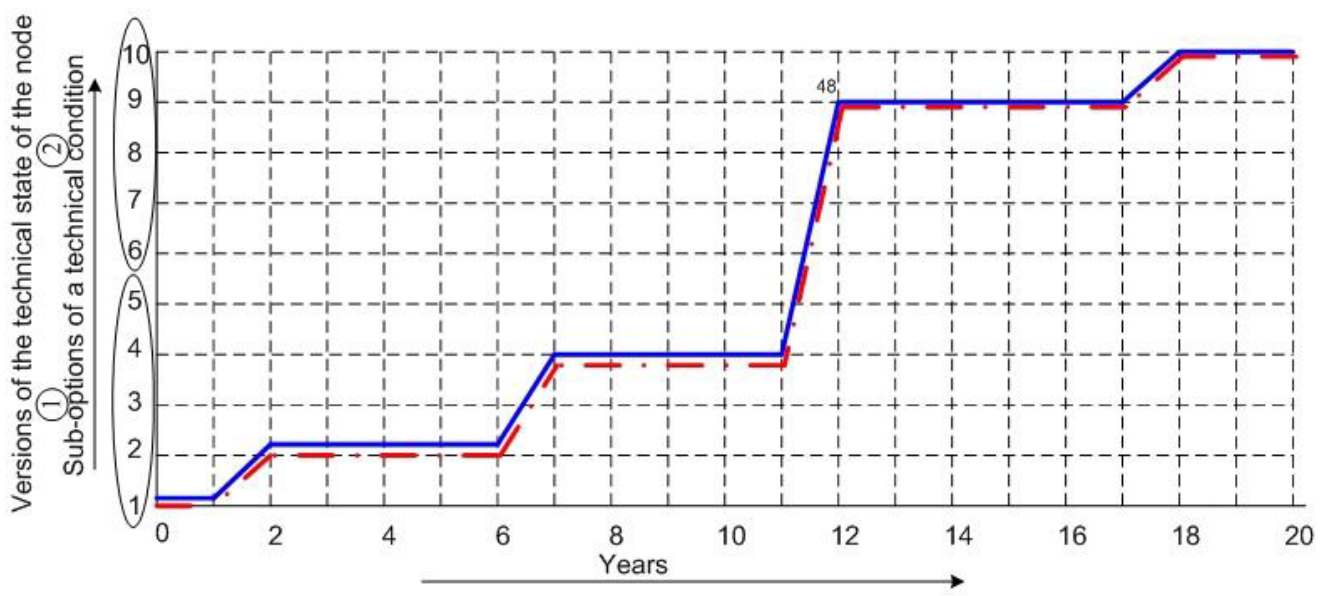

- the option of strengthening of the node

Figure 3. The dependence of the technical state of the node from the size of the movement with the same length of the bypass and intrasite course.

\section{Conclusion}

Received on the example of the conventional rail node, the results of justification of the construction of a bypass to skip the transit of freight trains, show that if the length of bypass node is less than the length of intrasite course, the construction of the bypass is undoubtedly effective. When the length of the bypass is more than the length of the intrasite turn the final decision should take into account the additional factors, and in excess of the cost of the bypass to $10 \%$ in comparison with the strengthening of intrasite course, should recommend the construction of a bypass, as this cost difference allows us to consider options for the development of the node, in terms of performance is virtually equal. However, the obtained results can be considered only as intermediate, a special case, 
because you have not defined the boundaries of the feasibility of building crawls with a significant number and range of influencing factors, the study of which can have great value and will be the subject of future research of the authors.

\section{References}

1. D.N. Kuklev, International Railway Journal 9, 20-23 (2015)

2. D.N. Kuklev, Railway Gazette International 4, 41-43 (2016)

3. D.N. Kuklev, International Railway Journal 11, 42-44 (2015)

4. J. Kolodziejski, Railway Gazette International 7, 32-34 (2016)

5. J. Kolodziejski, Railway Gazette International 8, 498-501 (2007)

6. J.P. Charlanne, Revue Générale des Chemins de Fer 149, 44-51 (2006)

7. Yu.I. Efimenko, Railway Gazette International 10, 785-790 (2008)

8. A.V. Sugorovskiy, Chinese Railways 1, 63-71 (2007)

9. J. Stagl, Progressive Railroading 4 (2009)

10. D.N. Kuklev, RGOTUPS 4, 37 - 41 (2006)

11. Yu.I. Efimenko, A.V. Sugorovskiy, Nauka i tekhnika transporta 4, 6- 12 (2010) 